\title{
Predicting and Assessing Work Performance of People with Limited Work Capacity (LWC): A Multi-Wave, Multi-Source Study
}

\author{
Gemma M. C. van Ruitenbeek ${ }^{1,2}$ (1) Fred R. H. Zijlstra ${ }^{1}$ - Ute R. Hülsheger ${ }^{1}$
}

Published online: 10 September 2020

(c) The Author(s) 2020

\begin{abstract}
Purpose Occupational integration is vital for the health of all people, also for people with Limited Work Capacity (LWC). Therefore, participation in regular work is a legal right for people that are restricted in their work capacity due to a disability and/or lack sufficient education. Full and effective integration is dependent on the person-job fit, and adequate vocational support should focus on meeting performance standards, as is common practice in traditional personnel selection and development programmes. Despite the huge amount of valid instruments for personnel selection and development, these tests are not suitable people with LWC. Recently, an instrument was developed for assessment and development purposes specifically for this target group. That study provided evidence for reliability and dimensionality this instrument. In our study, we add criterion-related measures to this instrument to demonstrate that assessment at $\mathrm{T} 1$ predict performance at $\mathrm{T} 2$, thus validating the instrument. Method We conducted a four-source data study, two sources for independent and two for outcome variables, to test the predictive validity of this instrument in a multi-wave setup. Results This study largely supports the validity of the instrument in predicting work behaviour and task performance of people with LWC. More specific, when measures are tailored to this target group, this group is able to predict their work behaviour and task performance accurately just like the general population. Conclusion We conclude that this instrument contributes to science, vocational support practices, and the personal and professional development of people with LWC, which is required for sustainable work.
\end{abstract}

Keywords People with disabilities and limitations - Work behaviour $\cdot$ Task performance $\cdot$ Personal and professional development $\cdot$ Multi-source feedback

\section{Introduction}

The psychological value of paid employment has been acknowledged for decades [1-3]. Employment is generally viewed to be conducive to mental health [4-6], whereas unemployment is associated with impaired mental health [6-10], with lower physical health [11], and with social isolation [12]. Employment should never be taken for granted, especially not for people with disabilities. The employment rate of people with disabilities remains far below that of people without limitations [13, 14], despite all public policies

Gemma M. C. van Ruitenbeek

gemma.vanruitenbeek@maastrichtuniversity.nl

1 Department of Work and Social Psychology, Maastricht University, Maastricht, The Netherlands

2 Department of Work and Social Psychology, Faculty of Psychology and Neuroscience, Maastricht University, P.O. Box 616, 6200 MD Maastricht, The Netherlands and legislations aimed at enabling workplace inclusion of people with disabilities [15]. We are referring to a group of people that has some kind of functional limitation. According to the International Classification of Functioning (ICF) [16], this is a rather diverse group which encompasses people with disabilities, but also people with low intellectual abilities, people with chronic diseases, and people with mental health issues that may vary from severe to 'mild' issues, such as attention deficit hyperactivity disorder (ADHD).

Participation in regular work of this target group is increased, but their employment is often of short duration $[17,18]$. This is often caused by poor person-job fit [19], or poor guidance concerning learning and development on the job [20,21]. Various approaches take the wishes and needs of specific target groups as point of departure in order to cover these concerns. Examples are the choose-get-keep approach [22], supported employment [23], and individual placement and support (IPS) [24], all for people with severe mental illness. Instruments that support methodical action 


\begin{tabular}{|c|c|c|c|c|}
\hline \multicolumn{2}{|r|}{$\mathrm{T} 1$} & \multirow{3}{*}{$\begin{array}{l}\text { Complete } \\
\text { matches }\end{array}$} & \multicolumn{2}{|l|}{$\mathrm{T} 2$} \\
\hline Sources & $\begin{array}{l}\text { Measures: } \\
\text { predictors }\end{array}$ & & $\begin{array}{c}\text { Measures: } \\
\text { outcome variables }\end{array}$ & Sources \\
\hline $\begin{array}{l}\text { Source 1: } \\
\text { Target } \\
\text { group }\end{array}$ & $\begin{array}{l}\text { Self-rated: } \\
\text { 1a. Planning \& organizing } \\
\text { 1b. Learning \& memory } \\
\text { 1c. Problem solving } \\
\text { 1d. Adaptability } \\
\text { 1e. Concentration } \\
\text { 2. Conscientiousness } \\
\text { 3a. Persistency } \\
\text { 3b. Self-confidence } \\
\text { 4a. Emotion-oriented coping } \\
\text { 4b. Task-oriented coping } \\
\text { 4c. Avoidance-oriented coping }\end{array}$ & & $\begin{array}{l}\text { Observer-rated: } \\
\text { 5a. Work accuracy } \\
\text { 5b. Work pace } \\
\text { 5c. Social behaviour at } \\
\quad \text { work }\end{array}$ & $\begin{array}{l}\text { Source 3: } \\
\text { Workplace } \\
\text { mentor of } \\
\text { target } \\
\text { group }\end{array}$ \\
\hline $\begin{array}{l}\text { Source 2: } \\
\text { Significant } \\
\text { other of } \\
\text { target } \\
\text { group }\end{array}$ & $\begin{array}{l}\text { Other-rated: } \\
\text { 1a. Planning \& organizing } \\
\text { 1b. Learning \& memory } \\
\text { 1c. Problem solving } \\
\text { 1d. Adaptability } \\
\text { 1e. Concentration } \\
\text { 2. Conscientiousness } \\
\text { 3a. Persistency } \\
\text { 3b. Self-confidence } \\
\text { 4a. Emotion-oriented coping } \\
\text { 4b. Task-oriented coping } \\
\text { 4c. Avoidance-oriented coping }\end{array}$ & & $\begin{array}{l}\text { Observer-rated: } \\
6 . \text { Task performance }\end{array}$ & $\begin{array}{l}\text { Source 4: } \\
\text { Supervisor } \\
\text { of target } \\
\text { group }\end{array}$ \\
\hline
\end{tabular}

Fig. 1 Study setup and sample size

of support providers of a broader group of people are lacking. Moreover, we argue that the performance standards in regular work should be the starting point, since the purpose is sustainable participation in regular work. Over decades, personnel psychologists have developed instruments that can facilitate the person-job fit and that can predict work performance [25-27], as these are important conditions for the duration of employment contracts. However, these instruments have been developed for the general population, and are not suitable for our target group. A person with functional illiteracy, for example, may be able to use familiar everyday expressions and very basic phrases, but is not able to fill-out complex questionnaires, and individuals with autistic spectrum disorders face difficulties with respect to metaphorical language often used in traditional personality questionnaires. Therefore, we need to design instruments with unambiguous and simple language.

In line with what the ICF model [16] assumes, human functioning is a result of a dynamic interaction between the limitation, personal characteristics and external factors. The dynamic interaction means that interventions directed at one aspect can cause changes in other related aspects. We therefore, plead for an instrument that includes both personal characteristics (such as coping style) and external factors (such as performance standards) in order to determine the direction of guidance.

Recently, Van Ruitenbeek et al. [28] have developed the Maastricht Work Capacity Monitor (MW@M) in an endeavour to facilitate selection, placement, and development of individuals with LWC, individuals like people of our target group. Although they provided evidence for the reliability and construct validity, the predictive validity has remained unaddressed. The overall goal of the present study is twofold. First, we will evaluate the predictive validity of the MW@M on performance standards such as work behaviour outcomes of our target group using a rigorous multi-source study in a longitudinal set-up (see Fig. 1). Second, we will extend the MW@M with measures of work behaviour and task performance that we adjusted to our target group.

In doing so, we make the following contributions to the literature: first and foremost, we draw attention to an important and yet understudied population that has the legal right to work and participate in the labour market but that has largely been ignored in the work and organisational psychology literature (for a recent exception see Vornholt et al. 2018) [15]. This is problematic, as organisations that are 
willing to employ people from the target group have insufficient means to select, place and train these people within their organisation because traditional personnel selection and development instruments are not designed for this specific population. We contribute to the work and organisational psychological literature as well as to the occupational rehabilitation literature, which will benefit from the availability of an adjusted and validated instrument to study the relationships between personality traits and work behaviour of people with LWC more accurately. Second, we expect that with our supplements, the MW@M can contribute to practice as it can enhance adequate assessment of the work capacity (personnel selection and matching person-job fit). We expect that it can contribute methodically to the continuous monitoring principle of supported employment interventions, such as IPS [29]. Third, we expect that our contribution will empower the field of work and organisational psychology and human resources practices to include people with LWC in paid employment.

Finally yet importantly, our target group can learn to reflect on their own strengths and weaknesses with the help of this instrument that consists of self-, other-, and observerratings forms. This helps to get an understanding of one's own work behaviour that can serve future behaviour, as an important driving force for learning [30-32]. This strengthens their personal and professional development, and sustainable integration into work.

\section{Point of Departure; Assessing Performance Standards of People with LWC}

As stated in the introduction, we argue that performance standards in regular work should be the point of departure when the purpose of our target group's sustainable participation in regular work. These standards are conditional for the continuation of their employment contract. There is a call for adequate and fair assessment instruments [33], and for more narrow and job-focused measures of performance that can be used for formal job appraisals as well as providing feedback to employees [33]. We argue that the task performance scale of Williams and Anderson [34] fits these criteria. This task performance scale also focuses on important work aspects such as quality and efficiency. We therefore adapted the task performance measure of Williams and Anderson [34] to reflect performance requirements for individuals with LWC.

Nearly every job, from cleaning services to ICT services, is performed in a customer or client service driven organisation nowadays. People need to display certain behaviour at work in order to be able to deliver the expected performance [35]. For that reason, we measure aspects of work behaviour itself that are relevant and expected to be displayed as part of every job alongside task performance. We argue that work behaviour and functioning should be measured adequately and fairly [36] for this specific population. The work behaviour inventory (WBI) [37] is an adequate instrument, that was developed for people with severe mental illness. We adapted the scale in order to make the scale more suitable for people with common mental disorders and disabilities.

The specific properties of the work behaviour and the task performance scales that we used in this study are described in the method section.

\section{Predictors of Work Behaviour of LWC}

An important question that has kept psychologists busy over the years is: what predicts work behaviour for the general population [25-27]? Special attention for predictors of work behaviour for people with LWC was seldom given. Van Ruitenbeek et al. [28] deliberately selected personal characteristics and personality traits relevant to the work capacity of individuals with LWC, and developed the MW@M. In choosing personality traits, they built upon extensive evidence from the work and organisational psychology literature and combined this with insights from the occupational rehabilitation literature. In this section, we complement their work and revisit the theoretical rationale for the choice of predictor variables included in the MW@M: mental ability, conscientiousness, self-efficacy and coping.

Several studies consider mental ability to be the most valid predictor of job behaviour [27, 38, 39]. General mental ability or intelligence reflects individuals' capability to reason logically, solve problems, make decisions, think abstractly, and learn [27, 38]. Nevertheless, the type of work and its context define the importance of mental ability [39], meaning that the required level of mental ability depends on the level of job complexity. Although logical reasoning and sophisticated problem solving skills are relevant for complex jobs, simple or routinized tasks require basic mental ability skills. In line with Van Ruitenbeek et al. [28], we argue that basic cognitive skills, such as planning and organising, learning and memory, adaptability, concentration, and basic problem solving, are important predictors of work behaviour for people with LWC. These aspects cover the key cognitive elements that can affect the ability to function in the workplace, and are assumed to be important aspects to include in assessment of work-capability [40]. Based on these considerations, we expect these five dimensions measured by self-rating and other-rating scales for people with LWC to be positively related to work behaviour and task performance.

Conscientiousness is one of the 'big five' personality traits that can be seen as a second powerful predictor of work behaviour [25-27]. Conscientious individuals are characterized by a high orientation to accomplish tasks, trustworthiness and cautiousness [25, 41, 42]. Among the "big 
five' traits, conscientiousness is the personality trait with the strongest predictive validity across different kinds of jobs and occupations including lower-level jobs [42]. We therefore argue, in line with Van Ruitenbeek et al. [28], that conscientiousness measured by self-rating and other-rating scales for people with LWC will be positively related to work behaviour and task performance.

The validity of self-efficacy has been demonstrated by several authors [43, 44]. Self-efficacy can be seen as the tendency to believe in one's own capacities and effectiveness to meet work demands in a variety of work settings [44-46]. Moreover, self-efficacy stipulates the course of action, the level of effort people put in, and their persistency [45, 47, 48]. It represents characteristics that demonstrated predictive validity to work-related behaviour for each level of task complexity across all included studies in a meta-analysis conducted by Stajkovic and Luthans [44]. The scales for people with LWC measure personal characteristics, such as self-confidence and persistence. These personal characteristics are important attributes for accomplishing work tasks [28]. In line with this reasoning, we expect that persistency and self-confidence measured by self-rating and other-rating scales for people with LWC will be positively related to work behaviour and task performance.

Finally, several authors consider self-regulation strategies to be important predictors of work behaviour [24, 49-51]. Coping can be seen as subset of self-regulation [52]. Coping refers to mental and behavioural effort people expose in order to master or decrease effects of stressors [53, 54]. Coping also reduces the impact of any kind of limitation or problem individuals face [55] as a consequence of their disability or disorder. Previous research has provided evidence for the positive relationship between self-regulation or self-management skills and work behaviour [49]. Although these studies have been conducted in the general population, Van Ruitenbeek et al. [28] argue that coping is an important predictor of work performance especially for people with LWC, since they have to deal with serious restrictions due to their functional limitation. The coping scale for people with LWC [28] is based on the shortened coping inventory for stressful situations (CISS-21) [56]. This three-factor structured coping scale refers to emotion-oriented coping, task-oriented coping, and avoidance-oriented coping. This model is grounded in the conceptualisation of coping as deliberate responses aimed at: (a) reducing stress through emotional reactions (emotion-oriented coping), or (b) solving the problem and attempting to change the situation (problem-focussed or task-oriented coping), or (c) seeking support and protection from others [57] and avoiding the stressful situation through distracting oneself with other situations or tasks (avoidance-oriented coping) [56]. In general, problem-focussed or active coping (i.e. task-oriented coping) has been shown to correlate with better adjustment, whereas emotion-oriented coping and withdrawal (avoidance-oriented coping strategies) have been found to be associated with poorer adjustment $[55,57]$. Therefore, we expect taskoriented coping to be positively related to work behaviour and task performance, whereas we expect emotion-oriented and avoidance-oriented coping strategies to be negatively related to work behaviour and task performance.

Taken together, the arguments presented above suggest that mental ability, conscientiousness, self-efficacy and coping assessed by self- and other-ratings at time 1 predict work behaviour and task performance at time 2 . We therefore hypothesise:

$\mathrm{H} 1$ The self-rating form of the MW@M measured at T1, consisting of scales for planning and organising, learning and memory, problem solving, adaptability, concentration, persistency, self-confidence, emotion-oriented coping, taskoriented coping and avoidance-oriented coping, predicts both (a) work behaviour and (b) task performance measured at $\mathrm{T} 2$.

$\mathrm{H} 2$ The other-rating form of the MW@M measured at T1, consisting of scales for planning and organising, learning and memory, problem solving, adaptability, concentration, persistency, self-confidence, emotion-oriented coping, taskoriented coping and avoidance-oriented coping, predicts both (a) work behaviour and (b) task performance measured at $\mathrm{T} 2$.

\section{Method}

We collected data from four different sources (i.e., target persons, significant others, workplace mentors and supervisors) in a multi-wave design in order to test the predictive validity of the MW@M-scales [28] on work behaviour and task performance. Specifically, we used four different sources of data: self- and other-ratings of independent variables (MW@M-scales for mental ability, conscientiousness, self-efficacy and coping) measured at time 1 , and ratings of the workplace mentor and the supervisor of outcome measures (such as work behaviour and task performance) at time 2 (see Fig. 1). People from the target group and their significant other (individuals that were chosen by the target persons themselves and who know the target person well, such as relatives or personal coaches) completed the self- and otherrating form of independent variables just before or in the first couple of days of work. After approximately 4 weeks of work, a workplace mentor completed a questionnaire assessing work behaviour, and the supervisor completed a questionnaire assessing task performance. The time span of approximately 4 weeks of work allows the target person to familiarise him- or herself with the work and work context 
and provides mentors, colleagues and supervisor with the opportunity to get to know the target person and his or her work behaviour and task performance. This time span also allows professionals to give feedback to our target group about their work behaviour and task performance in the first couple of workweeks in case a change in behaviour is needed. We deliberately chose the perspective of both mentors and supervisors, because the workplace mentor observes of the target person's day-to-day work behaviour and interacts with them, while the supervisor has more insights into work outcomes and performance levels.

We recruited participants from three vocational support providers in the Netherlands and the Dutch Employee Insurance Agency (Uitvoeringsinstituut Werknemersverzekeringen, abbreviated UWV). We collected data between November 2014 and February 2018.

\section{Procedure}

We contacted several vocational support providers and the UWV who offer vocational rehabilitation for people of our target group, and we presented the outline of the research project. Seven agencies with interest in collaborating received detailed information about the study and we asked job coaches and rehabilitation consultants to coordinate the participation of people from the target group. These coordinators registered the participants online in order to receive a registration code that enabled the target person, their significant other, their workplace mentor and the supervisor to fill in the online questionnaires. Prior to the questionnaires, participants were informed about the procedure and their rights with respect to the research in the online survey. The coordinator guided this process, which included, if necessary, the direct guidance of our target group when they filled-out the online questionnaire. Only fully accountable participants were included. They signed the online informed consent themselves. At time point one, the link to the online questionnaires for the self-rating and other-rating were distributed by e-mail. Four weeks after the target person had started working (time point two), workplace mentors and supervisors received online invitations to fill in the work behaviour and work outcome scales, respectively. Participants obtained a report of their individual results when the questionnaires were completed. The study has been approved by the local ethical review board.

\section{Participants}

People from the target group $(N=267)$ and their significant other $(N=199)$ completed a questionnaire that consisted of mental ability, conscientiousness, self-efficacy and coping scales. On average after 5.3 weeks of the target person starting to work, a workplace mentor completed the work behaviour questionnaire and the supervisor completed the task performance questionnaire. This resulted in complete matches for the self- and other-rated predictors and observerrated work behaviour, and task performance of $N=141$, 126,99 , and 89 respectively.

The self-report sample of complete matches of self-report (T1) and observer-report (T2) consisted of 141 self-ratings (64.5\% male, see Table 1). The mean age of the participants was $28.95(S D=10.02)$. More than three-quarters of the target group dealt with disabilities varying from a learning disability (25.9\%), $\mathrm{AD}(\mathrm{H}) \mathrm{D}$ or autism spectrum disorders (24.5\%), psychological disorder (15.8\%), physical (7.2\%) or other (3.6\% ; such as brain injury or dyslexia). Almost a quarter $(23 \%)$ of the target group did not report a disability. More than twenty percent $(21.9 \%)$ of the respondents reported comorbidity. Several people faced additional personal problems such as debts $(7.1 \%)$, housing problems $(2.4 \%)$, problems with childcare $(0.8 \%)$ or other personal problems $(3.1 \%$; such as dealing with grief or a disabled partner in combination with one's own disability). The level of education varied from lack of or insufficient vocational education (72.3\%), to low-level vocational education (13.9\%), intermediate or secondary level vocational education (11.7\%), and to high level education (2.2\%). More than ten percent (11.9\%) of the respondents had an employment contract, 32.2 percent had a learn-work agreement, 25.4 percent performed voluntary work, 25.4 percent worked in sheltered workplaces, and 5.1 percent worked during an internship. The work of the participants varied from simple duties in the care, service, or construction sector, to more complex administrative jobs.

The other-rating sample of complete matches of significant other (T1) and observer-report (T2) consisted of 126 other-ratings. Their relation to the target group varied from parent $(31.2 \%)$, partner $(5.6 \%)$, family member $(8.8 \%)$, friend $(10.4 \%)$, job coach $(10.4 \%)$, and personal coach $(29.6 \%)$ to a workplace mentor (4\%).

\section{Measures}

Mental ability was measured with the Vocational Cognitive Ratings Scale of Greig and colleagues [58], as adapted by Van Ruitenbeek et al. [28], consisting of five subscales: planning and organising, learning and memory, problem solving, adaptability, and concentration (e.g. "I complete tasks in a logical order.", "I can remember well how to do something.", or "I am easily distracted"). ${ }^{1}$

Conscientiousness was measured with the Dutch HEXACO personality inventory of De Vries et al. [59], as adapted by Van Ruitenbeek et al. [28], consisting of nine items (e.g.

\footnotetext{
${ }^{1}$ Items for the other-rating forms are formulated in the third person.
} 
Table 1 Descriptive statistics about the study population and the relation to their significant other

\begin{tabular}{|c|c|c|c|c|c|c|}
\hline & \multicolumn{4}{|c|}{ Self-rated sample $(\mathrm{N}=141)$} & \multicolumn{2}{|c|}{$\begin{array}{l}\text { Significant other sam- } \\
\text { ple }(\mathrm{N}=126)\end{array}$} \\
\hline & Mean & $S D$ & Range & Missing & Percentage & Missing \\
\hline Age (years) & 28.95 & 10.02 & $16-58$ & & & \\
\hline Gender ( $\%$ men $)$ & 64.5 & & & & & \\
\hline Disability in percentages & & & & 2 & & \\
\hline Not specified & 23.0 & & & & & \\
\hline Learning disability & 25.9 & & & & & \\
\hline $\mathrm{AD}(\mathrm{H}) \mathrm{D} /$ Autism spectrum disorder & 24.5 & & & & & \\
\hline Psychological & 15.8 & & & & & \\
\hline Physical & 7.2 & & & & & \\
\hline Different & 3.6 & & & & & \\
\hline Comorbidity & 21.9 & & & & & \\
\hline Problems & & & & 14 & & \\
\hline Housing & 2.4 & & & & & \\
\hline Childcare & 0.8 & & & & & \\
\hline Debts & 7.1 & & & & & \\
\hline Different (not specified) & 3.1 & & & & & \\
\hline Level of vocational education & & & & 4 & & \\
\hline Lack or insufficient & 72.3 & & & & & \\
\hline Low & 13.9 & & & & & \\
\hline Secondary & 11.7 & & & & & \\
\hline High & 2.2 & & & & & \\
\hline Type of contract & & & & 23 & & \\
\hline Regular contract & 11.9 & & & & & \\
\hline Learn-work agreement & 32.2 & & & & & \\
\hline Voluntary work & 25.4 & & & & & \\
\hline Probation period/internship & 5.1 & & & & & \\
\hline Sheltered workplace & 25.4 & & & & & \\
\hline Branch/type of industry & & & & 20 & & \\
\hline Administration & 11.3 & & & & & \\
\hline Cleaning & 3.5 & & & & & \\
\hline Care & 12.2 & & & & & \\
\hline Catering & 12.2 & & & & & \\
\hline Facilities & 20.0 & & & & & \\
\hline Logistics & 4.3 & & & & & \\
\hline Production & 25.2 & & & & & \\
\hline Retail & 5.2 & & & & & \\
\hline $\begin{array}{l}\text { Information and communication } \\
\text { technology (ICT)/media }\end{array}$ & 5.2 & & & & & \\
\hline Different & 0.9 & & & & & \\
\hline Relation to significant other & & & & & & 1 \\
\hline Parent & & & & & 31.2 & \\
\hline Partner & & & & & 5.6 & \\
\hline Family member & & & & & 8.8 & \\
\hline Friend & & & & & 10.4 & \\
\hline Job-coach & & & & & 10.4 & \\
\hline Personal coach & & & & & 29.6 & \\
\hline Workplace mentor & & & & & 4.0 & \\
\hline
\end{tabular}


"If I have to do something, I prepare it." or "I think carefully before making a decision.").

Self-efficacy was measured with the general self-efficacy scale (GSES-12) of Bosscher and Smit [45], as adapted by Van Ruitenbeek et al. [28], that consisted of two subscales: (a) persistency (six items, e.g. "Even if I don't like a task, I keep working on it until I'm done.") and (b) self-confidence (four items, e.g. "When I really want to do something, it goes wrong.").

The coping scale of Calsbeek and collegues (CISS-21) [56], as adapted by Van Ruitenbeek et al. [28], consisted of three subscales: (a) emotion-oriented coping (seven items, e.g. "If I have a problem or feel stressed, I blame myself for getting into that situation."), (b) task-oriented coping (six items, e.g. "If I have a problem or feel stressed, I try to remember if I have had the same problem before and how I solved it.", or "If I have a problem or feel stressed, I ponder if I can learn from it."), and (c) avoidance-oriented coping (three items, e.g. "If I have a problem or feel stressed, I buy something for myself.").

Work behaviour was measured by a scale that was inspired by the WBI [37]. The WBI was developed for people with severe mental illness. We translated the original English scale into Dutch, and adapted the scale in order to make it more suitable for people with common mental disorders and disabilities. We dropped items that were specifically related to severe mental illnesses (e.g. "Does not appear overly distant or aloof" or "Does not become overexcited or aggressive"). We also dropped items that reflect mental ability because they overlap with the independent mental ability scale. Before using the scale, supported employment experts verified the suitability of the scale for our target group and its relevance and applicability to the work situation. Given the changes we made to the original WBI scale, we tested the factor structure of the adapted scale. We subjected the data to exploratory factor analysis (EFA) using SPSS version 24. This process yielded a three-factor solution measuring, (a) work accuracy (seven items, e.g. "Arrives on time." and "Works precisely."), (b) work pace (four items, e.g. "Can keep up the work pace." and "When he/she has to work faster, he/she makes mistakes."), and (c) social behaviour at work (10 items, e.g. "Pays attention when listening to others." and "Consults with the person he/she works with."). We conducted a series of confirmatory factor analyses (CFA) and tested alternative models using Mplus version 7.3 following procedures recommended in literature $[60,61]$. Specifically, we tested a one-factor model with all items loading onto one factor $\left(\chi^{2}=814.262, d f=189, p<.000\right.$; CFI $=.649 ; \mathrm{TLI}=.610 ; \mathrm{RMSEA}=.151)$. We also tested this three-factor model with work accuracy loading on one, work pace on another and social behaviour at work loading on a third factor. Examination of fit indices indicated a poor fit for the work behaviour scale: $\chi^{2}=530.395, d f=186, p$
$=.000, \mathrm{CFI}=.807, \mathrm{TLI}=.785, \mathrm{RMSEA}=.113 . \mathrm{SRMR}$ $=.080(N=146)$. Inspection of the modification indices indicated that a better fit could be obtained by inclusion of four residual covariances. We accepted residual covariances because items were largely similar but at the same time, they indicated important subtle differences ("Arrives on time." and "Is present am at work as agreed."; "I work precisely" and "Makes sure he/she don't skip anything"; "Takes care of his/her appearance" and "I adjust my clothing to the work"; and finally "Works more slowly than others" and "When he/ she has to work faster, he/she makes mistakes"). The model fit indices improved substantially after this adaptation: $\chi^{2}$ $=328.333, d f=182, p=.000, \mathrm{CFI}=.918, \mathrm{TLI}=.905$ RMSEA $=.074$, SRMR $=.068$. We therefore treated work behaviour as a three-dimensional construct in this study.

For task performance, we adapted the task performance scale of Williams and Anderson [34]. We re-worded a few items from this original task performance scale in order to make it more applicable to the context of the target group. For example, we used "The work is done on time." instead of "Engages in activities that will directly affect his/her performance evaluation".

All scales were answered on a five-point Likert scale: 1 $=$ never, $2=$ almost never, $3=$ regularly, $4=$ almost always, $5=$ always.

\section{Analysis}

In order to explore the criterion-related validity of the selfratings and other-ratings of mental ability, conscientiousness, self-efficacy and coping on work behaviour and task performance, we first inspected zero-order correlations between the independent and dependent variables separately for each rating source.

Next, we conducted multiple regression analyses separately for the self- and other-ratings of independent variables using SPSS version 25. Since the traditional multiple regression approach has been criticized not to partition variance appropriately between various predictor variables, we also conducted relative weight analyses (RWA) [62], as it enabled us to test the relative importance of variables [63] using RWA-Web [64]. As recommended by Tonidandel and LeBreton [64], confidence intervals for the individual relative weights [65] and all corresponding significance tests were based on bootstrapping with 10,000 replications. Accelerated confidence intervals were used because of their superior coverage accuracy.

Before testing our hypothesis, we conducted a set of preliminary analyses to ensure that no violations of the assumptions of normality and linearity were made. We examined the critical Chi square values for evaluating Mahalanobis distance on outliers by using the number of independent (11) variables as the degrees of freedom [66, 67]. Results 
indicated three outliers with critical Chi square values above 31.26 in the self-rating sample. After deletion of these three cases, the final sample consisted of 138 participants.

\section{Results}

As can be seen from Table 2 (results of self-ratings) and Table 3 (results of other-ratings), results showed relatively low alphas for some independent variables. We therefore checked for the mean inter-item correlation for scales with alpha's below .7. The mean inter-item correlations of adaptability, conscientiousness and avoidance-oriented coping amounted respectively $.35, .22$ and .32 . As optimal mean inter-item correlation ranges from .2 to .4 [68]., all three fit these criteria.

The dimensions concentration and persistency were positively related to all outcome variables in both samples. This applies also to the relation between planning and organising and the outcome variables, except for the non-significant relation between planning and organising and task performance in the self-report sample. In the other-rating sample, conscientiousness was positively related to all outcome variables as well, whereas in the self-report, there was only a positive relation between conscientiousness and social behaviour at work.

In the self-report, only the positive relation between conscientiousness and social behaviour at work was significant. While no significant relation of learning and memory was found in the other-ratings, learning and memory was positively related to work pace in the self-report sample. Problem solving, on the other hand, correlated positively with work pace in the other-ratings, whereas no significant relation was found between self-rated problem solving and any outcome variable. Adaptability and emotion-oriented coping showed positive relations with work pace in both selfrating and other-rating forms. Task-oriented coping showed only significant and positive relations in other-ratings. Only avoidance-oriented coping showed a negative relation with task performance. Self-confidence showed significant and positive relations with work pace and social behaviour at work in the other-rating sample.

Results of multiple regression and relative weight analyses are reported together in Table 4 (self-rating) and Table 5 (other-rating). When considered jointly in a multiple regression analysis, self-ratings of all 11 dimensions explained between 16\% (work accuracy), 17\% (work pace), and 20\% (social behaviour at work) of variance in the respective aspects of work behaviour and $21 \%$ of variance in task performance. Owing to the intercorrelations between the 11 predictor dimensions, many individual beta-coefficients were not significant. A notable exception is self-reported avoidance-oriented coping, which was a significant negative predictor of all 4 outcome measures. Emotion-oriented coping was a significant negative predictor of work pace in multiple regression. Overall, multiple regressions regarding the self-rating report partly confirmed $\mathrm{H} 1$.

A somewhat different picture emerged when considering results of a multiple regression analysis in otherrating report. Here, other-rating reports of all 11 dimensions explained between $25 \%$ (work accuracy), $17 \%$ (work pace), and $16 \%$ (social behaviour at work) of variance in the respective aspects of work behaviour and $15 \%$ of variance in task performance. Owing to the intercorrelations between the 11 predictor dimensions, many individual betacoefficients were not significant in the other-rating sample. Notable exceptions were concentration and conscientiousness, which were significant predictors of work accuracy. With this, $\mathrm{H} 2$ is also partly confirmed.

An examination of the relative weights analysis of the self-rating report revealed that persistency $(\mathrm{RW}=.08)$ made the strongest unique contribution to the dimension social behaviour at work. It explained a statistically significant amount of variance in social behaviour at work as for the tests of significance the $95 \%$ CIs did not contain zero.

Examination of the relative weights of the other-rating report, revealed that both concentration $(\mathrm{RW}=.06)$ and conscientiousness $(\mathrm{RW}=.06)$ made the strongest contribution to work accuracy. Next in the contribution to work accuracy came learning and memory $(\mathrm{RW}=.03)$ and persistency $(\mathrm{RW}$ $=.03$ ). Adaptability made the strongest contribution to work pace $(\mathrm{RW}=.04)$.

\section{Discussion}

In this study, we aimed both to validate the predictive measures of the Maastricht Work Capacity Monitor (MW@M) of Van Ruitenbeek et al. [28], and to supplement this instrument with measures for work behaviour and task performance, in order to enhance human resource practices with respect to assessing the work capacity and the development of people with LWC.

We examined the relationship between the various personal characteristics and these two criterion variables (performance measures). Results showed corresponding significant correlations between the personal characteristics and the three dimensions of work behaviour and task performance in both self-report and other-rating report. Multiple regression analyses indicated in line with what we hypothesized, that avoidance-oriented coping was negatively related to all three work behaviour dimensions and to task performance in the self-report sample. Furthermore, corresponding to what we hypothesised, emotionoriented coping was negatively related to work pace, and persistency was positively related to social behaviour at 


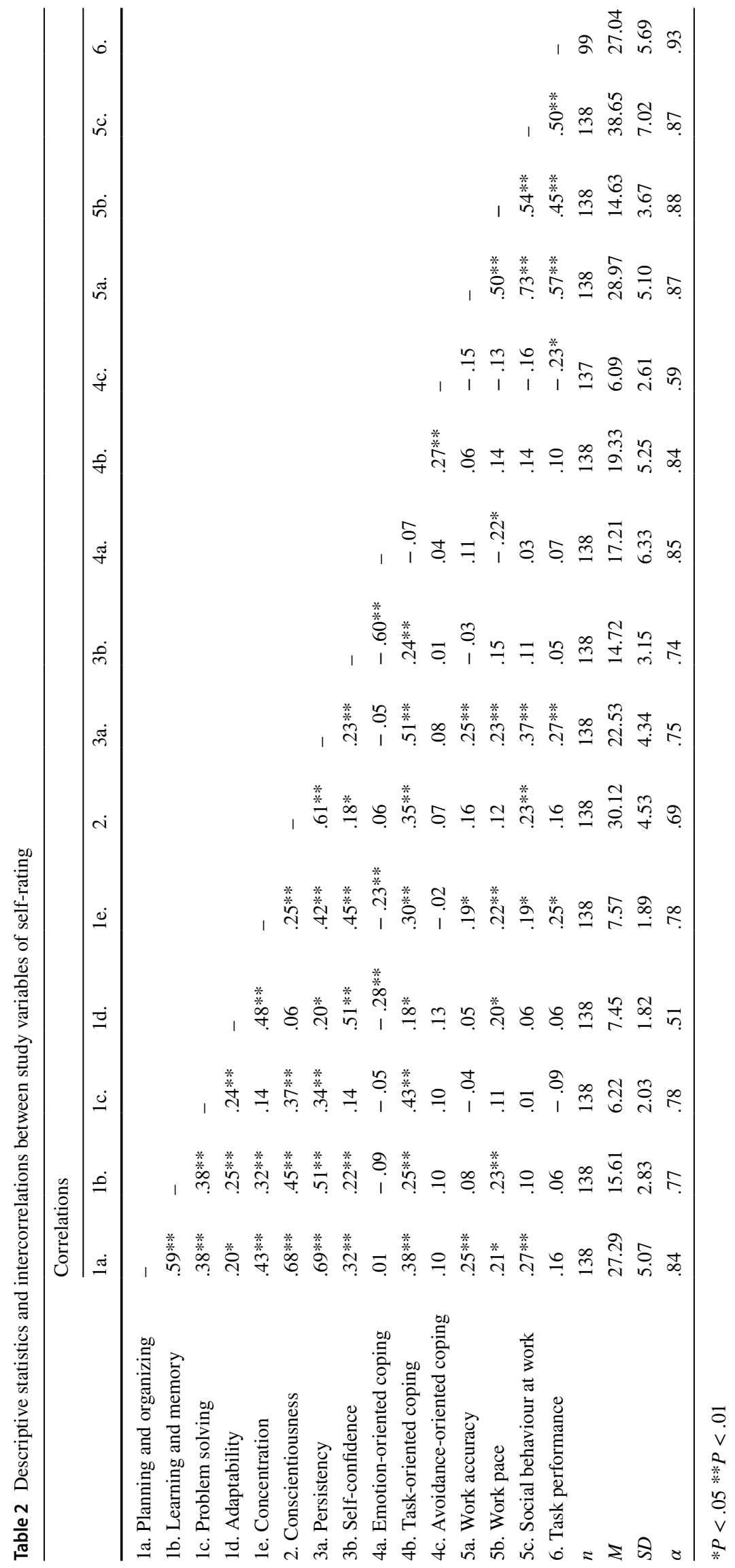




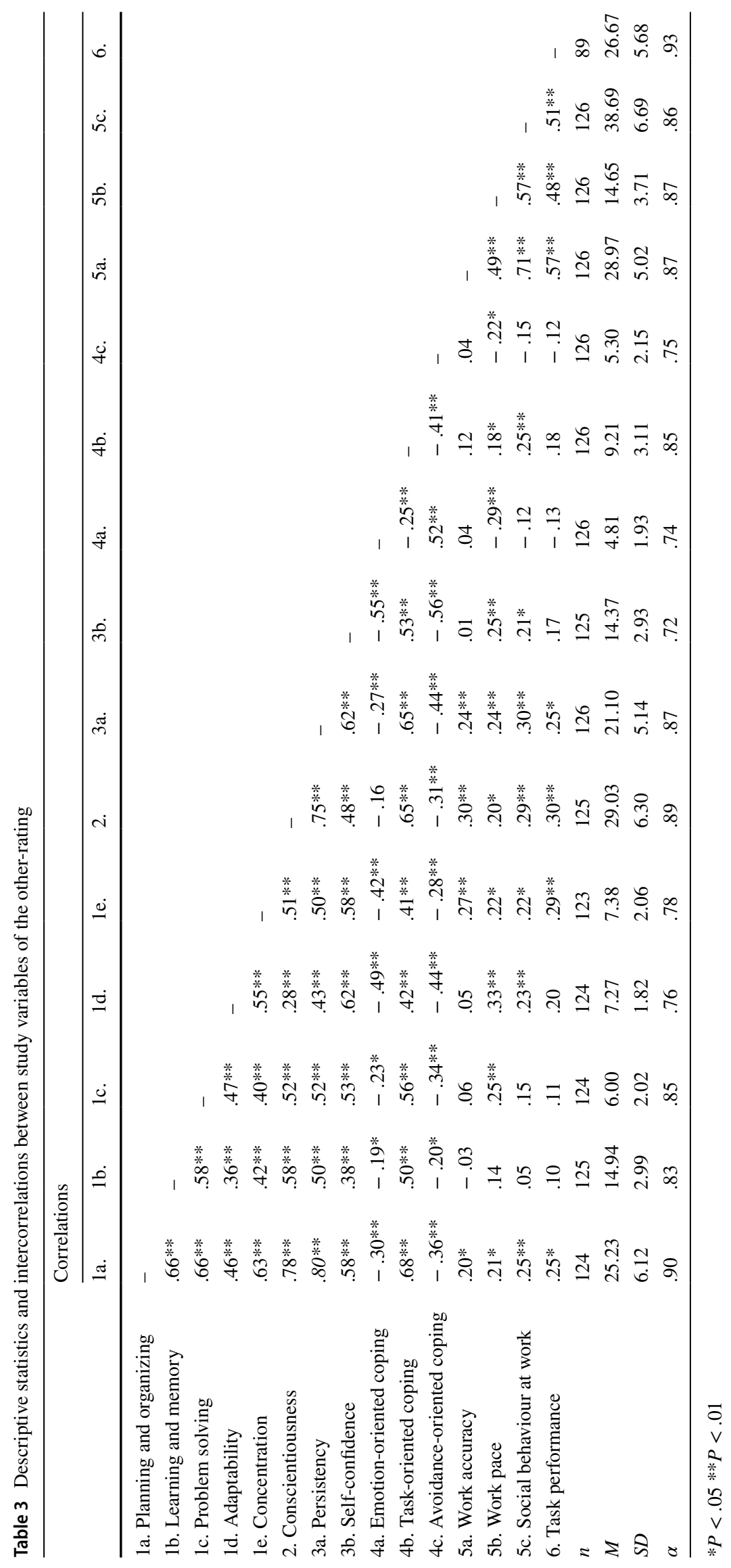


Table 4 Summary of multiple regression and relative weight analysis of the self-rating form

\begin{tabular}{|c|c|c|c|c|c|}
\hline Predictor & $\beta^{\mathrm{a}}$ & $\mathrm{RW}^{\mathrm{b}}$ & CI-L ${ }^{b}$ & $\mathrm{CI}-\mathrm{U}^{\mathrm{b}}$ & RS-RW $(\%)^{\mathrm{b}}$ \\
\hline \multicolumn{6}{|c|}{ Criterion $=$ work accuracy $\left(\mathrm{R}^{2}=.162 ; \mathrm{F}[11,125]=.912, \mathrm{p}<.018^{\mathrm{a}}\right)$} \\
\hline 1a. Planning and organizing & .26 & .036 & -.007 & .105 & 22.26 \\
\hline 1b. Learning and memory & -.10 & .005 & -.068 & .015 & 3.07 \\
\hline 1c. Problem solving & -.15 & .010 & -.034 & .060 & 6.30 \\
\hline 1d. Adaptability & .10 & .004 & -.060 & .022 & 2.66 \\
\hline 1e. Concentration & .10 & .018 & -.022 & .088 & 11.11 \\
\hline 2. Conscientiousness & -.02 & .010 & -.038 & .037 & 6.35 \\
\hline 3a. Persistency & .16 & .031 & -.008 & .088 & 19.11 \\
\hline 3b. Self-confidence & -.16 & .008 & -.045 & .038 & 5.17 \\
\hline 4a. Emotion-oriented coping & .06 & .009 & -.042 & .051 & 5.78 \\
\hline 4b. Task-oriented coping & .02 & .004 & -.062 & .015 & 2.44 \\
\hline 4c. Avoidance-oriented coping & $-.18^{*}$ & .026 & -.012 & .088 & 15.75 \\
\hline \multicolumn{6}{|c|}{ Criterion $=$ work pace $\left(\mathrm{R}^{2}=.165 ; \mathrm{F}[11,125]=.908, \mathrm{p}<.016^{\mathrm{a}}\right)$} \\
\hline 1a. Planning and organizing & .15 & .015 & -.008 & .070 & 9.19 \\
\hline 1b. Learning and memory & .11 & .020 & -.006 & .081 & 12.00 \\
\hline 1c. Problem solving & -.05 & .002 & -.025 & .025 & 1.25 \\
\hline 1d. Adaptability & .16 & .020 & -.007 & .088 & 12.16 \\
\hline 1e. Concentration & .04 & .014 & -.008 & .076 & 8.20 \\
\hline 2. Conscientiousness & -.04 & .004 & -.025 & .020 & 2.25 \\
\hline 3a. Persistency & .07 & .016 & -.010 & .067 & 9.35 \\
\hline 3b. Self-confidence & -.20 & .006 & -.019 & .026 & 3.73 \\
\hline 4a. Emotion-oriented coping & $-.25^{*}$ & .036 & -.004 & .145 & 21.84 \\
\hline 4b. Task-oriented coping & .10 & .008 & -.011 & .057 & 5.04 \\
\hline 4c. Avoidance-oriented coping & $-.19 *$ & .025 & -.006 & .129 & 14.99 \\
\hline \multicolumn{6}{|c|}{ Criterion $=$ social behaviour at work $\left(\mathrm{R}^{2}=.204 ; \mathrm{F}[11,125]=.866, \mathrm{p}<.002^{\mathrm{a}}\right)$} \\
\hline 1a. Planning and organizing & .08 & .027 & -.031 & .071 & 13.19 \\
\hline 1b. Learning and memory & -.12 & .007 & -.065 & .016 & 3.27 \\
\hline 1c. Problem solving & -.11 & .006 & -.062 & .020 & 3.02 \\
\hline 1d. Adaptability & .03 & .002 & -.069 & .012 & .90 \\
\hline 1e. Concentration & .01 & .011 & -.048 & .043 & 5.25 \\
\hline 2. Conscientiousness & .01 & .018 & -.046 & .039 & 8.88 \\
\hline 3a. Persistency & $.39^{* *}$ & $.083^{*}$ & .009 & .160 & 40.91 \\
\hline 3b. Self-confidence & .07 & .005 & -.063 & .020 & 2.50 \\
\hline 4a. Emotion-oriented coping & .09 & .004 & -.066 & .025 & 1.82 \\
\hline 4b. Task-oriented coping & .01 & .010 & -.057 & .030 & 4.90 \\
\hline 4c. Avoidance-oriented coping & $-.19 *$ & .031 & -.021 & .105 & 15.36 \\
\hline \multicolumn{6}{|c|}{ Criterion $=$ Task performance $\left(\mathrm{R}^{2}=.210 ; \mathrm{F}[11,86]=.906, \mathrm{p}<.030^{\mathrm{a}}\right)$} \\
\hline 1a. Planning and organizing & -.04 & .009 & -.078 & .030 & 4.45 \\
\hline 1b. Learning and memory & -.05 & .004 & -.091 & .019 & 1.83 \\
\hline 1c. Problem solving & -.21 & .022 & -.031 & .112 & 10.67 \\
\hline 1d. Adaptability & .06 & .005 & -.074 & .029 & 2.25 \\
\hline 1e. Concentration & .18 & .035 & -.016 & .127 & 17.50 \\
\hline 2. Conscientiousness & .07 & .011 & -.057 & .039 & 5.40 \\
\hline 3a. Persistency & .26 & .042 & -.026 & .132 & 19.99 \\
\hline 3b. Self-confidence & -.02 & .003 & -.089 & .015 & 1.32 \\
\hline 4a. Emotion-oriented coping & .13 & .009 & -.044 & .063 & 4.27 \\
\hline 4b. Task-oriented coping & .08 & .010 & -.059 & .048 & 4.69 \\
\hline 4c. Avoidance-oriented coping & $-.26^{*}$ & .058 & -.025 & .190 & 27.63 \\
\hline
\end{tabular}

$* p<.05 * * p<.01$

${ }^{a}$ Results from multiple regression analysis using SPSS version 25

${ }^{\mathrm{b}}$ Results form relative weight analysis using $\mathrm{R}$

$b$ unstandardized regression weight, $\beta$ standardized regression weight, RW raw relative weight (within rounding error raw weights will sum to $\mathrm{R}^{2}$ ), CI-L lower bound of confidence interval used to test the statistical significance of raw weight, CI-U upper bound of confidence interval used to test the statistical significance of raw weight, RS-RW relative weight rescaled as a percentage of predicted variance in the criterion variable attributed to each predictor (within rounding error rescaled weights sum to $100 \%$ ) 
Table 5 Summary of multiple regression and relative weight analysis of other-ratings

\begin{tabular}{|c|c|c|c|c|c|}
\hline Predictor & $\beta^{\mathrm{a}}$ & $\mathrm{RW}^{\mathrm{b}}$ & CI-L ${ }^{b}$ & $\mathrm{CI}-\mathrm{U}^{\mathrm{b}}$ & RS-RW $(\%)^{\mathrm{b}}$ \\
\hline \multicolumn{6}{|c|}{ Criterion $=$ work accuracy $\left(\mathrm{R}^{2}=.247 ; \mathrm{F}[11,109]=.829, \mathrm{p}<.001^{\mathrm{a}}\right)$} \\
\hline 1a. Planning and organizing & -.10 & .020 & -.007 & .043 & 8.23 \\
\hline 1b. Learning and memory & $-.34 * *$ & $.030^{*}$ & .001 & .108 & 12.32 \\
\hline 1c. Problem solving & .06 & .006 & -.023 & .033 & 2.42 \\
\hline 1d. Adaptability & .05 & .006 & -.024 & .026 & 2.30 \\
\hline 1e. Concentration & $.33 *$ & $.055^{*}$ & .006 & .143 & 22.08 \\
\hline 2. Conscientiousness & $.37 *$ & $.057 *$ & .013 & .128 & 22.87 \\
\hline 3a. Persistency & .26 & $.034 *$ & .003 & .087 & 13.76 \\
\hline 3b. Self-confidence & $-.31^{*}$ & .017 & -.006 & .070 & 6.84 \\
\hline 4a. Emotion-oriented coping & .02 & .005 & -.018 & .043 & 2.08 \\
\hline 4b. Task-oriented coping & -.03 & .009 & -.018 & .034 & 3.72 \\
\hline 4c. Avoidance-oriented coping & .11 & .008 & -.011 & .060 & 3.38 \\
\hline \multicolumn{6}{|c|}{ Criterion $=$ work pace $\left(\mathrm{R}^{2}=.165 ; \mathrm{F}[11,109]=.919, \mathrm{p}<.039^{\mathrm{a}}\right)$} \\
\hline 1a. Planning and organizing & -.17 & .006 & -.036 & .019 & 3.65 \\
\hline 1b. Learning and memory & -.07 & .003 & -.037 & .020 & 1.85 \\
\hline 1c. Problem solving & .17 & .019 & -.011 & .087 & 11.71 \\
\hline 1d. Adaptability & .24 & $.043 *$ & .003 & .121 & 25.97 \\
\hline 1e. Concentration & -.01 & .008 & -.015 & .044 & 4.95 \\
\hline 2. Conscientiousness & .18 & .0111 & -.014 & .056 & 6.73 \\
\hline 3a. Persistency & .15 & .013 & -.013 & .059 & 7.75 \\
\hline 3b. Self-confidence & -.13 & .009 & -.030 & .030 & 5.37 \\
\hline 4a. Emotion-oriented coping & -.22 & .039 & -.001 & .126 & 23.63 \\
\hline 4b. Task-oriented coping & -.06 & .004 & -.034 & .019 & 2.49 \\
\hline 4c. Avoidance-oriented coping & .01 & .010 & -.014 & .058 & 5.89 \\
\hline \multicolumn{6}{|c|}{ Criterion $=$ social behaviour at work $\left(\mathrm{R}^{2}=.159 ; \mathrm{F}[11,109]=.926, \mathrm{p}<.051^{\mathrm{a}}\right)$} \\
\hline 1a. Planning and organizing & -.02 & .015 & -.040 & .039 & 9.32 \\
\hline 1b. Learning and memory & $-.26^{*}$ & .016 & -.017 & .082 & 9.97 \\
\hline 1c. Problem solving & -.01 & .005 & -.061 & .018 & 3.22 \\
\hline 1d. Adaptability & .20 & .022 & -.019 & .094 & 13.85 \\
\hline 1e. Concentration & .03 & .011 & -.031 & .052 & 6.70 \\
\hline 2. Conscientiousness & .27 & .034 & -.013 & .097 & 21.62 \\
\hline 3a. Persistency & .15 & .026 & -.017 & .077 & 16.52 \\
\hline 3b. Self-confidence & -.08 & .007 & -.058 & .025 & 4.09 \\
\hline 4a. Emotion-oriented coping & -.03 & .003 & -.048 & .023 & 1.97 \\
\hline 4b. Task-oriented coping & .08 & .017 & -.022 & .067 & 10.78 \\
\hline 4c. Avoidance-oriented coping & .04 & .003 & -.059 & .021 & 1.95 \\
\hline \multicolumn{6}{|c|}{ Criterion $=$ Task performance $\left(\mathrm{R}^{2}=.148 ; \mathrm{F}[11,74]=.979, \mathrm{p}<.326^{\mathrm{a}}\right)$} \\
\hline 1a. Planning and organizing & -.04 & .014 & -.102 & .029 & 9.37 \\
\hline 1b. Learning and memory & -.15 & .006 & -.109 & .031 & 3.97 \\
\hline 1c. Problem solving & -.06 & .003 & -.121 & .022 & 2.30 \\
\hline 1d. Adaptability & .16 & .016 & -.076 & .060 & 10.65 \\
\hline 1e. Concentration & .17 & .032 & -.043 & .109 & 21.40 \\
\hline 2. Conscientiousness & .34 & .042 & -.039 & .133 & 28.75 \\
\hline 3a. Persistency & .06 & .016 & -.080 & .052 & 11.14 \\
\hline 3b. Self-confidence & -.13 & .005 & -.120 & .022 & 3.31 \\
\hline 4a. Emotion-oriented coping & -.04 & .004 & -.105 & .023 & 2.64 \\
\hline 4b. Task-oriented coping & -.03 & .007 & -.105 & .031 & 4.78 \\
\hline 4c. Avoidance-oriented coping & -.00 & .003 & -.104 & .024 & 1.68 \\
\hline
\end{tabular}

$* p<.05 * * p<.01$

${ }^{a}$ Results from multiple regression analysis using SPSS version 25

${ }^{\mathrm{b}}$ Results form relative weight analysis using $\mathrm{R}$

$b$ unstandardized regression weight, $\beta$ standardized regression weight, RW raw relative weight (within rounding error raw weights will sum to $\mathrm{R}^{2}$ ), CI-L lower bound of confidence interval used to test the statistical significance of raw weight, CI-U upper bound of confidence interval used to test the statistical significance of raw weight, RS-RW relative weight rescaled as a percentage of predicted variance in the criterion variable attributed to each predictor (within rounding error rescaled weights sum to $100 \%$ ) 
work. In the other-report sample, the expected positive relation between three predictors (learning and memory, concentration, and conscientiousness) and work accuracy was confirmed. However, in contrast with what we expected, self-confidence related negatively to work accuracy. This can be explained by the concern of practitioners that people from the target group tend to either over(in this case) or underestimate themselves [69].

Although avoidance-oriented coping turned out to be the strongest predictor in multiple regression analyses, the relative weight analysis showed that persistency had the strongest unique contribution. This means that persistency has a stronger impact on behavioural outcomes than the tendency to walk away (avoidance-oriented coping), and that makes perfect sense.

Overall, results obtained with the self-rating and other-rating forms, showed a similar amount of variance explained by the models as a whole ranging from $14.8 \%$ to $24.7 \%$. There were, however, some differences regarding the individual predictor-outcome relations between the self- and other-rating forms as well. This is in line with Connelly and Hülsheger [70]. These authors argue that research can benefit from collecting personality ratings from non-self-sources, such as significant others or other observers outside the work context. Our study also indicates that self- and other-rating perspectives are complementary. There is a strong tendency to look for self-other agreement in personality reports in literature [71], but we would like to make a case for 'celebrating the differences' in views. It is natural and functional that the 'self-perspective' differs from others' perspective. Therefore, we think that science and practice can be enriched by research that focusses on underlying reasons for the differences in perspectives instead of searching for the similarities.

It is interesting to note that self-rated avoidance-oriented coping showed negative predictive validity, whereas self-rated task-oriented coping showed no significant predictive validity in multiple regression. In the otherrating sample, however, positive correlations were found between task-oriented coping and two work behaviour dimensions. These findings can be explained by findings in a meta-analytic comparison of self- and informantreport study of Kim and colleagues [71], which implied that people are generally accurate but somewhat selfeffacing when rating their own personality traits.

Taken together, this study largely supported the validity of the MW@M in predicting work behaviour and task performance of people with LWC. It indicated that people with LWC are able to predict their own work behaviour accurately, similar to what is found in literature [71] regarding the general population.

\section{Practical Applications}

This study contributes to practice as self- and other perspectives of personal characteristics are essential to getting a grip on how people function. The different perspectives can sharpen one's view [70], so an instrument built upon multiple-source perspectives such as the extended MW@M, can enhance professional development of people with LWC. The fact that this study indicates that people with LWC are very well able to predict their work behaviour when scales are adapted is an important finding for professionals in the field (such as job coaches and vocational re-integration experts). These professionals can revise their persistent concern about the ability of people with LWC to reflect critically on their own behaviour and provide accurate responses. Professionals can now rely on validated measures that support talking with them instead of talking about them.

A noteworthy result is that self-rated avoidance-oriented coping stands out in negative predictive validity on all outcome variables. An explanation can be found in the fact that avoidance-oriented coping (e.g. looking for support from others, avoiding threat and searching security) is a natural coping response, whereas task-oriented coping (e.g. problem solving, and cognitive reframing or restructuring of a problem) is associated with more complex mental capacities [57]. It indicates that learned helplessness [72] is still a persistent phenomenon, and that the development of task-oriented coping gets too little attention. Apart from the above-mentioned practical implications, this indicates important directions for training, such as the call for practitioners to support people from the target group in the developing of task-oriented coping.

\section{Limitations and Future Research Directions}

A strength of our design was that we included multi-source measurements at two time points. A weakness may be that this leads to many dropouts, but we still have sufficient power in this study.

With respect to future directions of research, we think that the development over time of the work capacity of people with LWC needs to be monitored. This is precisely the added value of this instrument. Furthermore, Tables 2 and 3 showed high correlations between all three dimensions of work behaviour, and task performance. It would be worthwhile to explore this relation more accurately for people with LWC since this corresponds to the literature, stating that in order to be able to deliver the expected performance, people need to display certain behaviour at work [35]. 


\section{Conclusion}

To conclude, this study largely supports the predictive validity of the MW@M in predicting work behaviour and task performance. This study indicates that self- and otherrating perspectives are complementary to each other and it discusses the added value of research that focusses on the underlying reasons for disagreement between self- and other-report.

We argue that the extended MW@M enables adequate and fair performance evaluations of this specific population and contributes to science, by exploring the relationship between personality traits and work performance more accurately.

Moreover, this study contributes to vocational practices as it helps the continuous and methodological monitoring principle of supported employment interventions such as IPS [29] .

Finally, we argue that with the help of this instrument, our target group can learn to reflect on their own strengths and weaknesses. This enhances their personal and professional development and increases the chances for sustainable integration in work.

Funding This study was funded by the Dutch employee insurance agency UWV and supported by the Centre of Expertise for Inclusive Organisations (https://www.inclusiveworkredesign.com/).

\section{Compliance with Ethical Standards}

Conflict of interest Authors declare that they have no conflict of interest.

Ethical Approval All procedures performed in studies involving participants were in accordance with the ethical standards of the institutional and/or national research committee and with the 1964 Helsinki declaration and its later amendments or comparable ethical standards. Informed Consent Informed consent was obtained from all participants.

Open Access This article is licensed under a Creative Commons Attribution 4.0 International License, which permits use, sharing, adaptation, distribution and reproduction in any medium or format, as long as you give appropriate credit to the original author(s) and the source, provide a link to the Creative Commons licence, and indicate if changes were made. The images or other third party material in this article are included in the article's Creative Commons licence, unless indicated otherwise in a credit line to the material. If material is not included in the article's Creative Commons licence and your intended use is not permitted by statutory regulation or exceeds the permitted use, you will need to obtain permission directly from the copyright holder. To view a copy of this licence, visit http://creativecommons.org/licenses/by/4.0/.

\section{References}

1. Jahoda M. Work, employment, and unemployment: values, theories, and approaches in social research. Am Psychol. 1981;36(2):184-191.

2. Jahoda M. Employment and unemployment: a social-psychological analysis. Cambridge: Cambridge University; 1982.

3. Warr P. Work, unemployment, and mental health. New York: Oxford University Press; 1987.

4. Schuring M, Robroek SJW, Burdorf A. The benefits of paid employment among persons with common mental health problems: evidence for the selection and causation mechanism. Scand J Work Environ Heal. 2017;43(7):540-549.

5. Wanberg CR. A longitudinal study of the effects of unemployment and quality of reemployment. J Vocat Behav. 1995;46(1):40-54.

6. Warr P. A conceptual framework for the study of work and mental health. Work Stress. 1994;8(2):84-97.

7. Paul KI. The negative mental health effect of unemployment: meta-analyses of cross-sectional and longitudinal data. 2005.

8. Paul KI, Geithner E, Moser K. Latent deprivation among people who are employed, unemployed, or out of the labor force. J Psychol Interdiscip Appl. 2009;143(5):477-491.

9. Kim TJ, Von dem Knesebeck O. Perceived job insecurity, unemployment and depressive symptoms: a systematic review and meta-analysis of prospective observational studies. Int Arch Occup Environ Health. 2016;89(4):561-573.

10. Broom DH, D'Souza RM, Strazdins L, Butterworth P, Parslow R, Rodgers B. The lesser evil: bad jobs or unemployment? A survey of mid-aged Australians. Soc Sci Med. 2006;63(3):575-586.

11. McKee-Ryan FM, Song Z, Wanberg CR, Kinicki AJ. Psychological and physical well-being during unemployment: a metaanalytic study. J Appl Psychol. 2005;90(1):53-76.

12. World Health Organization (WHO). World report on disability. Geneva: World Health Organization; 2011.

13. Eurostat. Disability statistics—-labour market access. 2014. https ://ec.europa.eu/eurostat/statistics-explained/index.php?title=Archi ve:Disability_statistics_-_labour_market_access. Accessed 1 Feb 2020.

14. Eurostat. Smarter, greener, more inclusive? Indicators to support the Europe 2020 strategy. Eur. Union. Luxembourg; 2019.

15. Vornholt K, Villotti P, Muschalla B, Bauer J, Colella A, Zijlstra F, et al. Disability and employment-overview and highlights. Eur J Work Organ Psychol. 2018;27(1):40-55.

16. World Health Organization (WHO). International classification of functioning, disability, and health. Geneva: World Health Organization; 2001.

17. UWV. Duurzaamheid van banen binnen de Banenafspraak 20162017. Analyse op basis van het doelgroepregister en de polisadministratie [Sustainability of jobs within the 'Banenafspraak' 2016-2017. Analysis based on the target group registry]. Amsterdam; 2018.

18. Jehoel-Gijsbers G. Beperkt aan het werk [Getting to work with limitations]. Den Haag: Sociaal en Cultureel Planbureau; 2010.

19. Zijlstra FRH, Van Ruitenbeek GMC, Mulders HPG, Van Lierop B. Designing work for inclusiveness. In: Arenas A, Di Marco D, Munduate LEM, editors. Shap incl work through soc dialogue. Cham: Springer; 2017. p. 121-137.

20. Ministry of Social Affairs and Employment. Aan het werk, voor hoe lang? Onderzoek naar de begeleiding van jongeren met een arbeidsbeperking naar duurzaam werk [At work, for how long? Research into guidance of young people with limited work capacity towards sustainable jobs]. Den Haag: Inspectie SZW; 2018.

21. Bruyère SM, Erickson WA, VanLooy S. Comparative study of workplace policy and practices contributing to disability nondiscrimination. Rehabil Psychol. 2004;49(1):28-38. 
22. Danley KS, Anthony WA. The choose-get-keep approach to supported employment. Am Rehabil. 1987;13(4):6-9.

23. Bond GR, Becker DR, Drake RE, Rapp CA, Meisler N, Lehman $\mathrm{AF}$, et al. Implementing supported employment as an evidencebased practice. Psychiatr Serv. 2001;52(3):313-322.

24. Becker D, Whitley R, Bailey EL, Drake RE. Long-term employment trajectories among participants with severe mental illness in supported employment. Psychiatr Serv. 2007;58(7):922-928.

25. Barrick MR, Mount MK, Judge TA. Personality and performance at the beginning of the new millennium: what do we know and where do we go next? Int J Sel Assess. 2001;9(1-2):9-30.

26. Salgado JF, Viswesvaran C, Ones DS. Predictors used for personnel selection: an overview of constructs. In: Handbook of industrial, work and organizational psychology;2002.

27. Schmidt FL, Hunter JE. The validity and utility of selection methods in personnel psychology: practical and theoretical implications of 85 years of research findings. Psychol Bull. 1998;124(2):262-274.

28. van Ruitenbeek GMC, Zijlstra FRH, Hülsheger UR. The development of an instrument to measure the work capability of people with limited work capacity (LWC). J Occup Rehabil. 2019;29(1):163-174.

29. Van Ruitenbeek GMC. Praktijkhandleiding MW@M voor ggztrajectbegeleiders [MW@M manual for work coaches in Mental healthcare]. 2017.

30. Boud D, Keaogh R, Walker D. Reflection: turning experience into learning. London: Routledge; 1985.

31. Knipfer K, Kump B, Wessel D, Cress U. Reflection as a catalyst for organisational learning. Stud Contin Educ. 2013;35(1):30-48.

32. Moon JA. Reflection in learning and professional development: theory and practice. London: Routledge; 1999.

33. Arvey RD, Murphy KR. Performance evaluations in work settings. Annu Rev Psychol. 1998;49(1):141-168.

34. Williams LJ, Anderson SE. Job satisfaction and organizational commitment as predictors of organizational citizenship and in-role behaviors. J Manag. 1991;17(3):601-617.

35. Roe RA, Zijlstra FRH. Arbeidsanalyse ten behoeve van (her) ontwerp van functies: een handelingstheoretische invalshoek [Work analysis concerning (re-)design of work: an approach based on action theory]. In: Algera J, editor. Anal van Arb vanuit verschillende perspectieven. Amsterdam: Swets \& Ze; 1991. p. 179-244.

36. Zijlstra FRH. Work performance. In: Fernandez-Ballesteros R, editor. The encyclopedia of psychological assessment. London: Sage Publications; 2002. p. 1107-1113.

37. Bryson G, Bell MD, Lysaker P, Zito W. The work behavior inventory: a scale for the assessment of work behavior for people with severe mental illness. Psychiatr Rehabil J. 1997;1(24):1-16.

38. Schmidt FL, Hunter J. General mental ability in the world of work: occupational attainment and job performance. J Pers Soc Psychol. 2004;86(1):162-173.

39. Gottfredson LS. Why g matters: the complexity of everyday life. Intelligence. 1997;24(1):79-132.

40. Fadyl JK, Mcpherson KM, Schlüter PJ, Turner-Stokes L. Factors contributing to work-ability for injured workers: literature review and comparison with available measures. Disabil Rehabil. 2010;32(14):1173-1183.

41. Wanberg CR, Hough LM, Song Z. Predictive validity of a multidisciplinary model of reemployment success. J Appl Psychol. 2002;87(8):1100-1120.

42. Barrick MR, Mount MK. The big five personality dimensions and job performance: a meta-analysis. Pers Psychol. 1991;44(1):1-26.

43. Bono JE, Judge TA. Core self-evaluations: a review of the trait and its role in job satisfaction and job performance. Eur J Pers. 2003;17(S1):S5-S18.
44. Stajkovic AD, Luthans F. Self-efficacy and work-related performance: a meta-analysis. Psychol Bull. 1998;124(2):240-261.

45. Bosscher RJ, Smit JH. Confirmatory factor analysis of the General Self-Efficacy Scale. Behav Res Ther. 1998;36(3):339-343.

46. Chen G, Gully SM, Eden D. General self-efficacy and self-esteem: toward theoretical and empirical distinction between correlated self-evaluations. J Organ Behav. 2004;25(3):375-395.

47. Bandura A. Self-efficacy: toward a unifying theory of behavioral change. Psychol Rev. 1977;84(2):191-215.

48. Locke EA. Self-efficacy: the exercise of control. Pers Psychol. 1977;50(3):801.

49. Frayne CA, Geringer JM. Self-management training for improving job performance: a field experiment involving salespeople. J Appl Psychol. 2000;85(3):361-372.

50. Michon HWC, van Weeghel J, Kroon H, Schene AH. Illness selfmanagement assessment in psychiatric vocational rehabilitation. Psychiatr Rehabil J. 2011;35(1):21-27.

51. Cunningham K, Wolbert R, Brockmeier MB. Moving beyond the illness: factors contributing to gaining and maintaining employment. Am J Commun Psychol. 2000;28(4):481-494.

52. Eisenberg N, Fabes RA, Guthrie IK. Coping with stress. In: Wolchik S, Sandler IN, editors. Handbook of children's coping. Boston, MA: Springer; 1997. p. 41-70.

53. Folkman S, Lazarus RS. An analysis of coping in a middle-aged community sample. J Health Soc Behav. 1980;21(3):219-239.

54. Schreurs PJ, Tellegen B, Willige GV. Gezondheid, stress en coping: de ontwikkeling van de Utrechtse coping-lijst [Health, stress and coping: de development of The Utrecht Coping list]. Tijdschr voor Psychol. 1984;12:101-117.

55. Calsbeek H, Rijken M, Bekkers MJTM, Van Berge Henegouwen GP, Dekker J. Coping in adolescents and young adults with chronic digestive disorders: impact on school and leisure activities. Psychol Health. 2006;21(4):447-462.

56. Calsbeek H, Rijken P, Van Berge GP, Henegouwen M, Dekker J. Factor structure of the Coping Inventory for Stressful Situations (CISS-21) in adolescents and young adults with chronic digestive disorders. In: Calsbeek H, editor. The social position of adolescets and young adults with chronic digestive disorders. Nivel; 2003.

57. Compas BE, Connor-Smith JK, Saltzman H, Thomsen AH, Wadsworth ME. Coping with stress during childhood and adolescence: problems, progress, and potential in theory and research. Psychol Bull. 2001;127(1):87-127.

58. Greig TC, Nicholls SS, Bryson GJ, Bell MD. The Vocational Cognitive Rating Scale: a scale for the assessment of cognitive functioning at work for clients with severe mental illness. J Vocat Rehabil. 2004;21(2):71-81.

59. De Vries RE, Lee K, Ashton MC. The Dutch HEXACO personality inventory: psychometric properties, self-other agreement, and relations with psychopathy among low and high acquaintanceship dyads. J Pers Assess. 2008;90(2):142-151.

60. Furr M. Scale construction and psychometrics for social and personality psychology. Thousand Oaks: SAGE Publications Ltd; 2011.

61. Byrne BM. Structural equation modeling with AMOS: basic concepts, applications, and programming. New York: Routledge; 2016.

62. Johnson JW. A heuristic method for estimating the relative weight of predictor variables in multiple regression. Multivar Behav Res. 2000;35(1):1-19.

63. Tonidandel S, LeBreton JM. Relative importance analysis: a useful supplement to regression analysis. J Bus Psychol. 2011;26(1):1-9.

64. Tonidandel S, LeBreton JM. RWA web: a free, comprehensive, web-based, and user-friendly tool for relative weight analyses. J Bus Psychol. 2015;30(2):207-216. 
65. Johnson JW. Factors affecting relative weights: the influence of sampling and measurement error. Organ Res Methods. 2004;7(3):283-299.

66. Pallant J. SPSS survival manual. London: McGraw-Hill Education; 2013.

67. Tabachnick BG, Fidell LS. Using multivariate statistics. Boston: Pearson; 2013.

68. Briggs SR, Cheek JM. The role of factor analysis in the development and evaluation of personality scales. J Pers. 1986;54(1):106-148.

69. Centraal Expertise Centrum UWV. Ontwikkelingsstoornissen wajong. Richtlijn voor verzekeringsgeneeskundig onderzoek en beoordeling van ontwikkelingsstoornissen in de wet Wajong [IDevelopmental disorders. Guideline for medical research and assessment of developmental disorders]. Amsterdam; 2010.
70. Connelly BS, Hülsheger UR. A narrower scope or a clearer lens for personality? examining sources of observers' advantages over self-reports for predicting performance. J Pers. 2012;80(3):603-631.

71. Kim H, Di Domenico SI, Connelly BS. Self-other agreement in personality reports: a meta-analytic comparison of self- and informant-report means. Psychol Sci. 2019;30(1):129-138.

72. Seligman MEP. Learned helplessness. Annu Rev Med. 1972;23(1):407-412.

Publisher's Note Springer Nature remains neutral with regard to jurisdictional claims in published maps and institutional affiliations. 